Bangl. J. Vet. Med. (2011). 9(1): 17 - 25

\title{
PATHOLOGICAL STUDY ON COLIBACILLOSIS IN CHICKENS AND DETECTION OF ESCHERICHIA COLI BY PCR
}

\author{
N.S. Tonu, M. A. Sufian, S. Sarker, M.M. Kamal, M.H. Rahman and M.M. Hossain* \\ Department of Pathology, Faculty of Veterinary Science, Bangladesh Agricultural University, \\ Mymensingh-2202, Bangladesh
}

\begin{abstract}
The aim of the present study was to detect the pathogenic Escherichia coli (E. coli) through pathological study of the colibacillosis affected birds. These isolated $E$. coli were further confirmed by PCR using specific primer. For this purpose, a total of 20 swabs (10 from lung and 10 from intestine of 10 dead birds) were collected in sterile nutrient broth. The histopathological samples were collected in $10 \%$ buffered neutral formalin. The used methods were histopathology, isolation and identification of $E$. coli by conventional methods and as well as by PCR method. A total of 10 isolates of E. coli from 20 swabs of lung and intestine was characterized by conventional routine methods of bacteriology. Gross pathological lesions of all lungs in the present investigation were congested and consolidated. Duodenum showed congestion and hemorrhages with excess mucus in the luminal surface of it. Microscopically, all the lungs showed severe congestion, infiltration of heterophils, macrophages and lymphocytes in the wall of bronchus as well as in the peribronchial alveoli. E. coli infected all the duodenum showed severe infiltration of leukocytes mainly heterophils, lymphocytes and macrophages in the submucosa of the duodenal wall. In this study, DNA of 8 isolates out of 10 isolated E. coli organisms was amplified by PCR using ECO-f and ECO-r primer targeting $16 \mathrm{~S}$ ribosomal DNA and found $585 \mathrm{bp}$ amplicon which is specific for $E$. coli with enteroinvasive type confirmed by histopathological lesions in duodenum. Further investigation should be focused on serotyping and detection of genes of $E$. coli which are responsible for pathogenicity of the organism.
\end{abstract}

Key words: Colibacillosis, histopathologcal, chickens, PCR

\section{INTRODUCTION}

Bangladesh livestock population statistics indicates poultry as the most important species of birds in this country. A total of $98.15 \%$ of poultry are kept in rural area and they are scavengers (BBS, 1987). For the last several years, poultry rearing has been developed as an industry in Bangladesh. With great expansion of the poultry rearing and farming, colibacillosis has become wide spread problem in Bangladesh like other areas of the world (Talha et al., 2001; Islam et al., 2003 and Rahman et al., 2004). Heavy economic loss occurs in both broiler and layer due to morbidity, mortality, reduced production and chick quality. Mortality may rich up to 94\% in severe outbreak of colibacillosis ( McPeake et al., 2005 and Biswas et al., 2006).

The organisms of $E$. coli are divided into pathogenic and nonpathogenic based on their ability to cause diseases. Pathogenically, E. coli strains are due to the presence of one or more virulence factors including invasiveness factors invasins, heat labile, heat stable enterotoxins, verotoxins and colonization factors or adhesins (Smith and Haibs, 1967). Pathogenic E. coli are divided into two types namely as enteropathogenic $E$. coli and uropathogenic E. coli. Further pathogenic E. coli are grouped into enterotoxigenic E. coli (ETEC), enteropathogenic E. coli (EPEC), enteroinvasive E. coli (EIEC), enteroaggregative E. coli (EAggEC), enterohaemorrhagic E. coli (EHEC). Uropathogenic E. coli cause $90 \%$ of the urinary tract infection. The bacteria colonize from the faeces or perineal region and ascend the urinary tract to the bladder of the animals (Carter, 1986).It is quite difficult to differentiate the pathogenic strains from that of the nonpathogens on the basis of antigenic, structural and biochemical characteristics (Dupont et al., 1971). It is not known whether the pathogenic activity is determined entirely or in part by the host. If the host plays the dominant part, then any normal or wild strain of $E$. coli will be able to assume a pathogenic role. Therefore, it urges for the separation of pathogenic strains from the nonpathogenic one (Levine, 1984).

*Corresponding e-mail address: mmhossain04@yahoo.com.au

Copyright ( 2011 Bangladesh Society for Veterinary Medicine 


\section{N.S. Tonu and others}

Pathogenic E. coli are usually identified by detection of a specific virulence factor or of a serotype associated with a virulence factor. Over 700 antigenic types (serotypes) are recognized based on $0, \mathrm{H}$ and $\mathrm{K}$ antigens. Different serological test such as fluorescent antibody test (FAT), enzyme-linked immunosorbent assay (ELISA) test, serum agglutination test (SAT), growth inhibition test (GIT) are used for the detection of enterotoxigenic and enteropathogenic E. coli (Klipstein, 1984). Different molecular techniques such as nucleic acid hybridization and polymerase chain reaction (PCR) studies can also be used to detect pathogenic E. coli and DNA probes directed at a number of genes have also been developed (Wani et al., 2003). In vitro pathogenicity test for $E$. coli is determined by using congo red binding activity (Ahmad et al., 2009).Various parameters including the prevalence, isolation identification and epidemiological investigation of all type of pathogenic and nonpathogenic E. coli were studied in Bangladesh by different authors (Choudhury and Rahman, 1967; Mostofa, 1998). Detection of avian pathogenic of E. coli was not systematically and properly focused by the previous research works in the context of Bangladesh. The use of molecular techniques has several advantages compared with the classical culture methods for enumerating bacteria; one major advantage is the rapidity and sensitivity of the determination compared with culture methods. Perhaps the most serious drawback of the culture- based methods is that only a small fraction of bacteria can be found; up to $99 \%$ of the bacteria in many environments fail to grow under artificial conditions (Amann et al., 1995). Amplification of DNA sequences unique to organisms using the PCR improves both the speed of detection and the level of sensitivity at which organisms can be detected and has been increasingly used to identify several bacterial species from food and clinical samples. Another advantage is that PCR is not dependent on the utilization of a substrate or the expression of antigens, thereby circumventing phenotypic variations in biochemical patterns and lack of detectable antigens. The use of PCR for rapid diagnosis is inevitable for the control of disease in poultry farms of Bangladesh.

To our knowledge many investigations have been performed on pathogenicity test of $E$. coli through animal inoculation but molecular detection of avian pathogenic E. coli has not been performed in our country. In this study a primer set targeting E. coli $16 \mathrm{~S}$ rDNA gene has been used for the detection of E. coli. Therefore, the present research work was performed with these objectives (a) pathological studies of colibacillosis affected dead birds. (b) isolation and identification of E. coli from the collected sample of dead birds. (c) detection of pathogenic E. coli using specific primer.

\section{MATERIALS AND METHODS}

\section{Samples}

A total of 10 dead birds from Krishibid Poultry Farm, Bhaluka (8 birds) and S.K. Diagnostic Center (SKDC), Mymensingh ( 2 birds) and a total of 20 swabs samples (10 from lung and 10 from intestine) were collected from necropsy cases during the study period from June 2009 to January 2010.

\section{Culture in different media}

All lung and intestinal swabs were placed in nutrient agar plate and incubated for overnight at $37^{\circ} \mathrm{C}$ for the growth of the organisms. After primary culture of the organisms, a small amount of inoculum from nutrient agar were subcultured in the nutrient agar and MacConkey agar to observe the colony morphology. Characteristic colony morphology of the organisms indicating the features of E. coli was selected for subculture on EMB agar (Carter, 1986). Morphological characteristics (shape, size, surface texture, edge and elevation, color, opacity etc. of the suspected colonies on different agar media developed within 18 to 24 hours of incubation were carefully studied and recorded.

\section{Gram's stain}

Gram's staining was performed as per recommendation of Merchant and Packer (1967) to determine the size, shape and arrangement of bacteria.

\section{Motility test}

The motility test was performed according to the method described by Cowan, (1985) to differentiate the motile bacteria from the non-motile one by hanging drop preparation. 


\section{Sugar fermentation test}

The sugar fermentation test was performed by inoculating $5 \mathrm{ml}$ of nutrient broth culture of the organisms into the tubes containing different sugar media and incubated for 72 hours at $37^{\circ} \mathrm{C}$. Acid production was indicated by the color change from red to yellow of the medium and the gas production was noted by the appearance of gas bubbles in the inverted Durham's tube.

\section{Methyl red test procedure}

After incubation 2-4 drops of methyl red solution were added to the test which was incubated for 5 days at $37^{\circ} \mathrm{C}$ for MR test. Positive test was indicated by the persistence of red color, indication of acidity and the negative one by the yellow color.

\section{Voges-Proskauer (V-P) test procedure}

The VP test was performed by adding $0.6 \mathrm{ml}$ of VP reagent- 1 and $0.2 \mathrm{ml}$ of VP reagent-2 for each $\mathrm{ml}$ of culture. The ingredients were mixed thoroughly and allowed to stand for a while. The appearance of pink color indicated to positive test.

\section{Gross lesions}

The postmortem examination was performed for the lung and intestine of dead birds. At necropsy, gross tissue changes were observed and recorded carefully, and representative tissue samples containing lesions were fixed in $10 \%$ neutral buffered formalin for histopathological studies (Stubbs, 1954).

\section{Histopathology}

The formalin-fixed tissues were trimmed, processed, sectioned and stained as per standard procedure (Luna, 1968). Specific lesions containing samples were used in histopathological study.

\section{Detection of Escherichia coli (E. coli) by PCR Oligonucleotide primers}

For PCR analysis of locally isolated E. coli, oligonucleotide primers targeting 16S rDNA gene (Candrian et al., 1991; Amit-Romach et al., 2004) (Science Park Rd. \#01-23, The Gemini, S'pore) ECO-f and ECO-r were used (Table 1).

Table 1. Primers were used for the detection of the $E$. coli

\begin{tabular}{|crc|}
\hline Primer & Primer sequence $\left(5^{\prime}-3^{\prime}\right)$ & Amplification products (bp) \\
\hline ECO-f & GACCTCGGTTTAGTTCACAGA & 585 \\
ECO-r & CACACGCTGACGCTGACCA & 585 \\
\hline
\end{tabular}

\section{DNA extraction and Quantification of DNA concentration}

DNA was extracted from E. coli isolate using Wizard Genomic DNA Purification Kit (Promega, Madison, WI, USA) and extracted DNA was quantified by using spectrophotometer (DU-640, Beckman, Germany) on the basis of optical density ratio at 260: $280 \mathrm{~nm}$.

\section{DNA amplification}

PCR amplification was performed in a final volume of $20 \mu \mathrm{l}$ containing $4 \mu \mathrm{l}(50 \mathrm{ng} / \mu \mathrm{l})$ of DNA template, Taq buffer- B $2 \mu \mathrm{l}$, dNTPs $2 \mu \mathrm{l}(250 \mathrm{mM})$, primer-F $1 \mu \mathrm{l}(100 \mathrm{mM})$, primer-R $1 \mu 1(100 \mathrm{mM})$, Taq DNA polymerase $0.4 \mu \mathrm{l}(3 \mathrm{U} / \mu \mathrm{l})$ and 8.4 $\mu \mathrm{l}$ nuclease free water (Science Park Rd.\#01-23 The Gemini, S'pore). Three independent reactions, with the primers, were made for DNA template. Amplification was carried out in Gene amplification PCR system 9600 Thermocycler (Master cycler eppendorf, Germany). Initial denaturation was at $94^{\circ} \mathrm{C}$ for 3 min., followed by 35 cycles for $94^{\circ} \mathrm{C}$ for $30 \mathrm{sec}$., annealing at $60^{\circ} \mathrm{C}$ for $1 \mathrm{~min}$ and extension at $68^{\circ} \mathrm{C}$ for $2 \mathrm{~min}$, with a final extension at $68^{0} \mathrm{C}$ for 7 minutes and hold for $4^{0} \mathrm{C}$. 


\section{N.S. Tonu and others}

\section{Agarose gel Electrophoresis}

Amplified products were separated by electrophoreses on $1 \%$ agarose gel containing ethidium bromide. The agarose gel was prepared using $1 \mathrm{gm}$ agarose powder (Fisher Biotech, New Jersey, USA and Genei, Banglore India), 100ml 1X TAE buffer and 5 $\mu$ l ethidium bromide. Agarose gel electrophoresis was conducted in 1X TAE buffer at $100 \mathrm{~V}$ for 35 minutes. $100 \mathrm{bp}$ ladder (Ggibco BRL) as molecular weight marker and loading dye $(0.25 \%$ xylene cyalon, $0.25 \%$ bromophenol blue, $30 \%$ glycerol and $1 \mathrm{mM}$ EDTA) were used for electrophoresis. Bands were observed under UV light on a transilluminator and photographed by image documentation system (Labortechnic, Germany).

\section{Photomicrography}

Photomicrography was taken at the Department of Pathology using photomicrographic camera (Olympus PMC 35 Model) onto fitted with Olympus microscope (Olympus, Japan).

\section{Data interpretation}

At the end of the study period all findings were compiled, scrutinized and analyzed for comprehensive interpretation.

\section{RESULTS AND DISCUSSION}

\section{The colony characters of identified bacteria}

The present study was conducted primarily identification of pathogenic E. coli by molecular detection in dead chickens. E.coli is an adaptive species that is both a commensal resident of the intestine and a versatile pathogen of humans and other animals, causing enteric infections and particular pathologies in different animal species (Dozois et al., 2003). The stress factors of any types may enhance the virulence of $E$. coli with production of diseases (Talha et al., 2001). Therefore, for animal and human health, there is great importance in developing a method that will enable accurate and rapid identification of the above bacteria. A total of 10 isolates of E. coli from 20 swabs of lung and intestine was characterized by conventional routine methods of bacteriology. Rose pink colored colonies on MacConkey agar (Fig. 1) and greenish colonies with metallic sheen on EMB agar produced by the organisms (Fig.2) after overnight incubation were confirmed as E. coli. In this study, the colony characters of all isolated E. coli, were the production of metallic sheen on the EMB agar and rose pink color colonies on the MacConkey agar which corresponded with the findings of other ( Sharada et al., 1999).

\section{Gram's stain}

Light microscopic examination of all 10 isolates after Gram's staining revealed Gram-negative, pink colored, short rod shaped organisms arranged as single or in pair (Fig.3). The morphology of the isolated bacteria from 10 isolates exhibited Gram negative, pink color, short rod to coccoid shape and in the hanging drop technique all the isolates revealed motile. These findings supported the findings of several authors (Merchant and Packer, 1967 and Khoskhoo and Peighambari, 2004).

\section{Motility test}

All 10 isolates of $E$. coli isolates were found to be motile with 'hanging drop' preparation under microscope. These findings supported the findings of several authors (Merchant and Packer, 1967 and Khoskhoo and Peighambari, 2004).

\section{Sugar fermentation test and Other biochemical tests}

All 10 isolates of $E$. coli fermented dextrose, lactose, maltose and mannitol with the production of acid and gas (Table 2) but did not ferment inositol. Acid production was indicated by the color changes of the sugar media from reddish to yellow and the gas production was noted by the accumulation of gas bubbles in the inverted Durham's tube (Table 2). All the isolates were methyl red positive and Voges-Proskauer test negative (Table 2). In the present study, the entire isolated $E$. coli organisms revealed a complete fermentation of those sugars and the organisms were motile but did not ferment inositol. These findings also supported the findings of several authors (Shinebaum and Cooke, 1985 and Beutin et al., 1997). In the present study, the results of methyl red test of 10 isolates of $E$. coli were positive but Voges-Proskauer test was negative which were also similar to the findings of other author (Thomas, 1988). 
Table 2. Biochemical characteristics of E. coli

\begin{tabular}{|cccccccccc|}
\hline $\begin{array}{c}\text { No. of } \\
\text { isolates }\end{array}$ & $\begin{array}{c}\text { Methyl red } \\
\text { test (MR } \\
\text { test) }\end{array}$ & $\begin{array}{c}\text { Voges- } \\
\text { proskauer test } \\
\text { (VP test) }\end{array}$ & $\begin{array}{c}\text { Motility } \\
\text { test }\end{array}$ & DX & L & ML & MN & $\begin{array}{c}\text { Name of } \\
\text { isolated } \\
\text { bacteria }\end{array}$ \\
\hline 10 & + & - & + & AG & AG & AG & AG & E. coli \\
\hline
\end{tabular}

Legends: $\quad \mathrm{DX}=$ Dextrose, $\mathrm{L}=$ Lactose,$\quad \mathrm{ML}=$ Maltose,$\quad \mathrm{MN}=$ Mannitol,$\quad \mathrm{AG}=$ Acid and gas,$\quad+=$ Positive, - = Negative

\section{Gross lesions}

Postmortem findings revealed congested and consolidated lung (Fig. 5) in some chickens. The duodenum showed mucus (Fig.4), congestion and hemorrhages (enteritis) and all these lesions were categorized into septicaemic from. The severity of gross lesions was variable in all the dead birds in the present study corresponded with the findings of other investigators (Talha et al., 2001; Islam et al., 2003 and Ghosh et al., 2006).

\section{Microscopic lesions}

The section of lungs showed severe congestion, infiltration of heterophils, macrophages and lymphocytes in the wall of the bronchus as well as in the peribronchial alveoli (Fig.6). In lungs granuloma were also present. In duodenum, severe infiltration of leukocytes mainly heterophils, lymphocytes and macrophages in the submucosa of the duodenal wall were observed. Enlarged mucosal glands were also observed (Fig. 7). Microscopically, all dead birds did not reveal homogenous severity of lesions in all organs in the present study corresponded with the findings of others (Talha et al., 2001; Islam et al., 2003 and Ghosh et al., 2006).

E. coli causes severe types of disease conditions such as colisepticemia, coligranuloma (Hjarre's disease), avian cellulites (inflammatory process), air sacculitis, swollen head syndrome, enteritis, pericarditis, peritonitis, salpingitis, osteomyelitis/ synovitis, panophthalmitis and omphalitis / yolk sac infection (Chauhan, 1996 and Barens and Gross, 1997). In the present study all the reported forms of colibacillosis were not recorded. However, the recorded forms of colibacillosis could be categorized into septicaemic form with enteritis and air sacculitis. E. coli singly does not produce typical gross lesions. The lesions are most prominent when simultaneously infected with other organisms such as Mycoplasma. E. coli can produce diseases becoming attached with mucosal epithelia and another form by invasion to the mucosal epithelia. The recorded lesions of intestine were in the form of degeneration, necrosis and desquamation of mucosal epithelia associated with severe inflammation. On the basis of the recorded lesions, the form of colibacillosis in the present study could be categorized into enteroinvasive form of colibacillosis. These types of histopathological lesions in recorded forms of colibacillosis were supported by different authors (Talha et al., 2001; Islam et al., 2003 and Ghosh et al., 2006).

\section{Detection of Escherichia coli (E. coli) by PCR}

Locally isolated 8 isolates (out of 10) of E. coli were tested by ECO-f and ECO-r primer and showed 585-bp products from each field samples after $1 \%$ agarose gel electrophoresis (Fig. 8). Traditionally, diagnosis of colibacillosis was carried out by isolation and identification of E. coli. The isolation and identification depend upon the culture of the organism using different selective media and biochemical tests. Instead of biochemical and ELISA tests, PCR and its related method have been reported to identify E. coli. The PCR is used as a highly sensitive and specific test for the presence of pathogenic bacteria in clinical specimens (Cohen et al., 1993). PCR is also more rapid, reliable than traditionally culture methods (Carli et al., 2001).We also found the similar results in the present study. In this study, the isolated E. coli organisms from all collected birds were grown in nutrient broth, extracted DNA and amplified by PCR using ECO-f and ECO-r primer targeting E. coli $16 \mathrm{~S}$ ribosomal DNA and found $585 \mathrm{bp}$ amplicon after $1 \%$ agarose gel electrophoresis. The similar result also found other authors (Amith-Romach et al., 2004). This base pair is specific for E. coli not for others. 


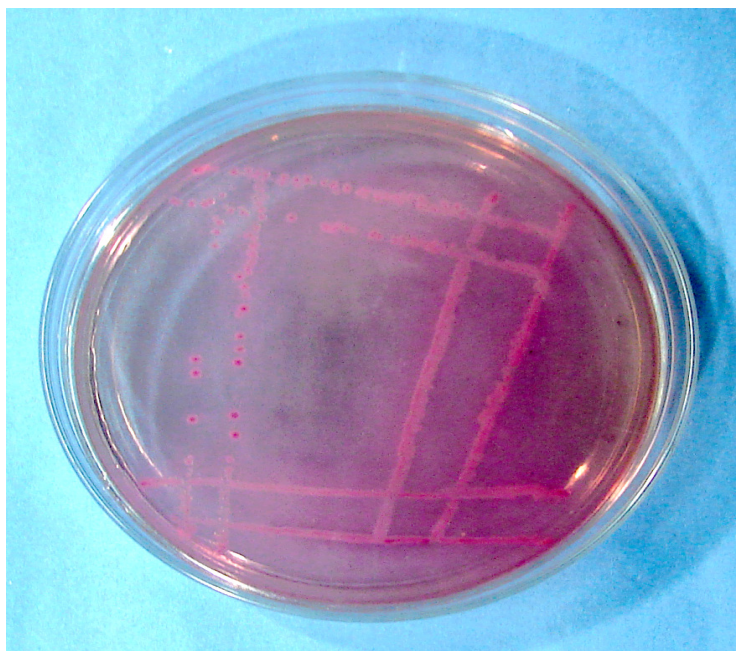

Fig. 1. E. coli isolates showing rose pink colored colonies on MacConkey agar

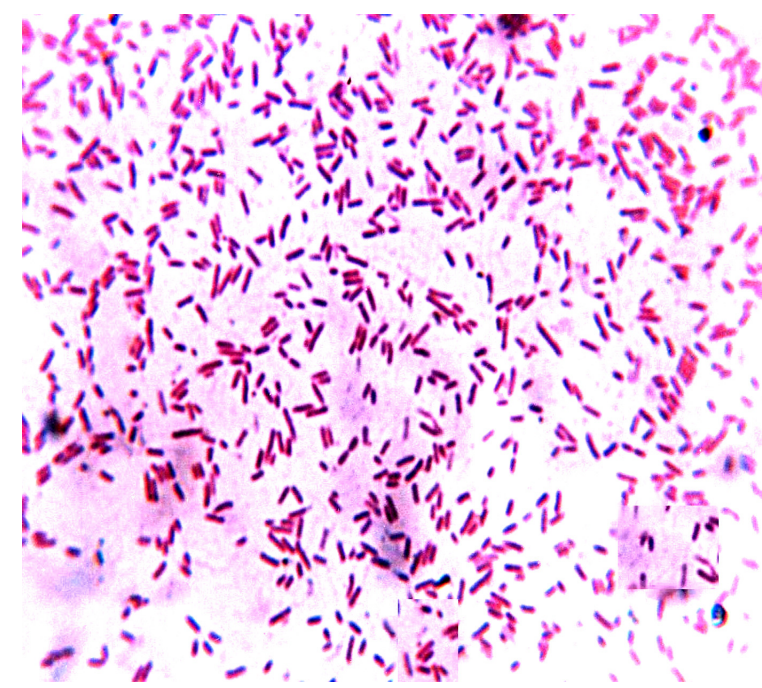

Fig. 3. Isolated E. coli in Gram's straining (microscopic) showing Gram negative, pink color, short rod shape organisms, arranged in single or paired (Modified Gram's Stain, $\times 830$ )

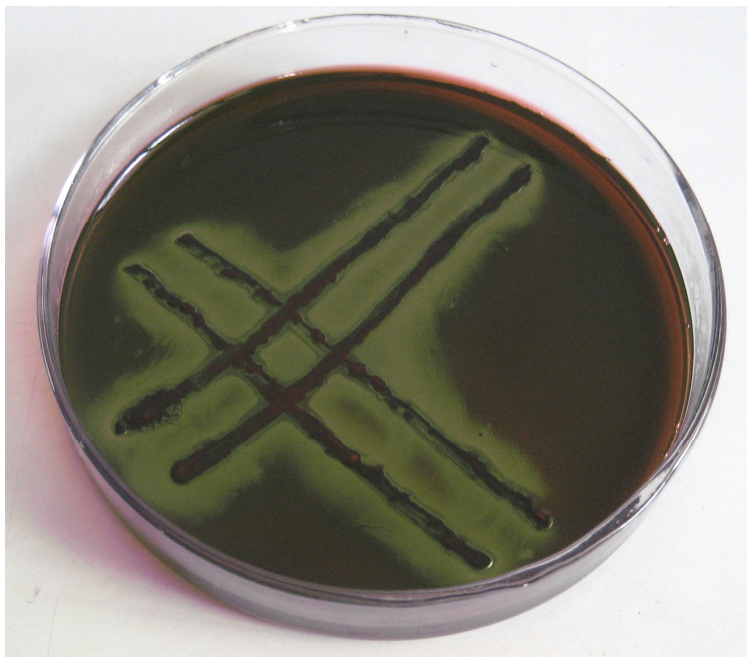

Fig. 2. Isolation of E. coli showing characteristics greenish colored colonies with metallic sheen on EMB agar

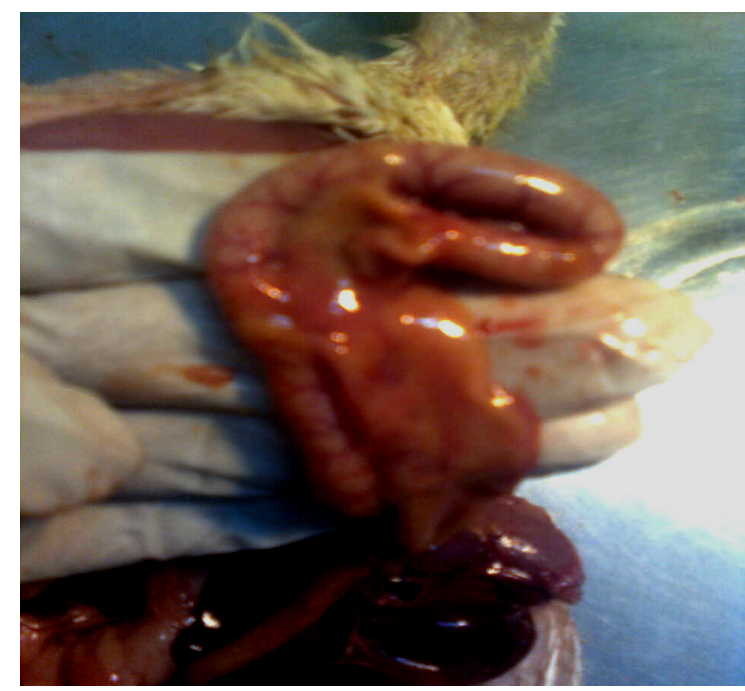

Fig. 4. E. coli infected chickens showing the duodenum congestion, hemorrhages and excess mucus 


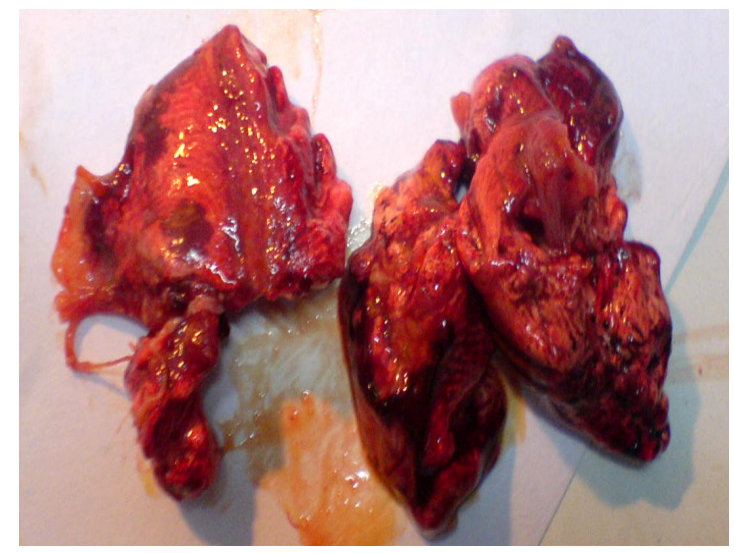

Fig. 5. Lungs of E. coli infected chickens showing congestion and consolidation

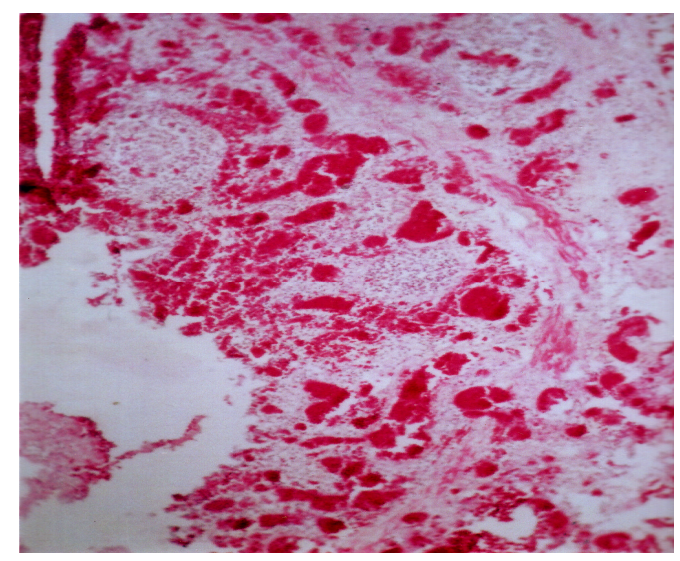

Fig. 6. The section of lung in E. coli infection showing severe congestion and infiltration of heterophils, macrophages and lymphocytes in the wall of the bronchus as well as In the peribronchial alveoli (H \& E staining, $\times 83$ )

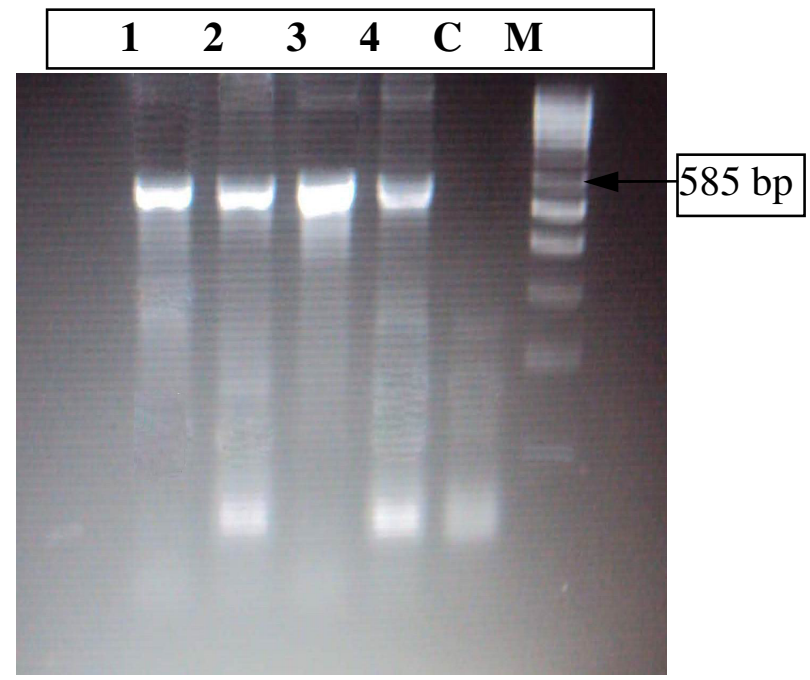

Fig. 8. Electrophoresis on agarose gel showing the $585 \mathrm{bp}$ PCR product (from lane 1 to lane 4) after amplified in field samples of locally isolated $E$. coli and lane $\mathrm{C}$ and lane $\mathrm{M}$ showing the negative control and marker, respectively 


\section{REFERENCES}

1. Ahmad MD, Hashmi RA, Anjum AA, Hanif A and Ratyal RH (2009). Drinking water quality by the use of congo red medium to differentiate between pathogenic and non pathogenic E. coli at poultry farms. Lahore, Pakistan. The Journal of Animal \& Plant Sciences 19(2): 108-110.

2. Amann R, Ludwig W and Schleifer K (1995). Phylogenetic identification and in situ detection of individual microbial cells without cultivation. Microbiology Revista 59:143-169.

3. Amit-Romach E, Sklan D and Uni Z (2004). Microflora Ecology of the Chicken Intestine Using 16S Ribosomal DNA Primers. Poultry Science 83:1093-1098.

4. Barens JH. and Gross WB (1997). Colibacillosis, In: Diseases of Poultry. Edited by: Calnec, B. W. $10^{\text {th }}$ edn. Lowa University Press Ames, Lowa, USA. pp. 131-141.

5. BBS (1987). Bangladesh Bureau of statistics. The Bangladesh Census of Agriculture and Livestock. 1983-84.

6. Beutin L, Geier D, Zimmeronann S, Aleksic S, Gillespie HA and Whittam TS (1997). Epidemiological relatedness and clonal types of natural population of $E$. coli strains producing shiga toxins in separate population of cattle and sheep. Applied and Environmental Microbiology 63: 2175-2180.

7. Biswas PK, Uddin GMN, Barua H, Roy K, Biswas D, Ahad A and Debnath NC (2006). Causes of loss of Sonali chickens on smallholder households in Bangladesh. Preventive Veterinary Medicine 76: 185-195.

8. Candrian U, Furrer B, Hofelein C, Meyer R, Jermini M and Luthy J (1991). Detection of Escherichia coli and identification of enterotoxigenic strains by primer-directed enzymatic amplification of specific DNA sequences. International Journal of Food Microbiology 12:339-351.

9. Carli KT, Ulan CB, Caner V, Eyigor A (2001). Detection of Salmonellae in Chicken Feces Combination of Tetrathionate Broth Enrichment, Capillary PCR, and Capillary Gel Electrophoresis. Journal of Clinical Microbiology 39 (5): 1871-1876.

10. Carter GR (1986). Essentials of Veterinary Bacteriology and Mycology. $3^{\text {rd }}$ edn. pp. 312-330.

11. Chauhan HVS (1996). Poultry Diseases, Diagnosis and Treatment. $2^{\text {nd }}$ edn. International (P) Limited, Publishers. Bangalore. pp. 30-36.

12. Choudhury T and Rahman M (1967). Microflora of milk in a single herd. Pakistan Journal of Veterinary Science 1:3.

13. Cohen ND, Neibergs HL, Mcgruber ED, Whitford HW, Behle RW, Ray PM, Hargis BM, (1993). Genusspecific detection of Salmonellae using the polymerase chain reaction (PCR). Journal of Veterinary Diagnosis \& Investigation 5: 368-371

14. Cowan ST (1985). Biochemical behavior of E. coli. Journal of General Microbiology 8: 391.

15. Dozois CMF and Curtiss R (2003). Identification of pathogen-specific and conserved genes expressed in vivo by an avian pathogenic Escherichia coli strain. Proc. Natl. Acad. Sci. USA. 100:247-252.

16. Dupont HL, Formal SB, Hornick KB, Sayder MM, Libonati JP, Sheahar DG, Labrec EH and Kalas JP (1971). Pathogenesis of Escherichia coli diarrhoea. The New England Journal of Medicine 28: 1-9.

17. Ghosh RC, Hirpurkar SD and suryawnshi PR (2006). Concurrent colibacillosis and infectious bursal disease in broiler chicks. Indian Veterinary Journal 83: 1019-1020.

18. Islam MR, Das BC, Hossain KH, Lucky NS and Mostafa MG (2003). A study on the occurrence of poultry disease in Sylhet Region of Bangladesh. International Journal of Poultry Science 2: 354-356.

19. Khoshkhoo PH and Peighambari SM (2004). Characteristics of Escherichia coli isolated from cases of avian colibacillosis. Journal of the Faculty of Veterinary Medicine, University of Tehran 59: 233-240.

20. Klipstein (1984). Enzyme linked immunosorbant assay for Escherichia coli heat stable enterotoxin. Journal of Clinical Microbiology 19: 798-803.

21. Levine MM(1984). Escherichia coli infections. Garmander ( ed ), Bacterial vaccines Academic Press, Inc. New. York. pp.187-235.

22. Luna LG (1968). Manual of Histologic Staining Methods of the Armed Forces Institute of Pathology. $3^{\text {rd }}$ edn. McGraw Hill Book Co. New York, USA.

23. McPeake SJ, Smyth JA and Ball HJ (2005). Characterisation of avian pathogenic Escherechia coli (APEC) associated with colisepticaemia compared to faecal isolates from healthy birds. Veterinary Microbiology 110: $245-53$. 
24. Merchant IA and Packer RA (1967). Veterinary Bacteriology and Virology. $7^{\text {th }}$ edn. The Iowa State University Press, Ames, Iowa, USA. pp.211-305.

25. Mostofa AM (1998). Diarrhoea due to enterotoxigenic Escherichia coli in zebu \& cross breed calves \& its public health significance. MS. Thesis . Department of Microbiology \& Hygiene. Faculty of Veterinary Science, BAU, Mymensingh.

26. Rahman MA, Samad MA, Rahman MB and Kabir SMI (2004). Bacterio pathological studies on salmonellosis, colibacillosis and pasteurellosis in natural and experimental infections in chickens. Bangladesh Journal of Veterinary Medicine 2: 1-8.

27. Sharada R, Krishnappa G, Raghavan R, Sreevinas G and Upandra HA (1999). Isolation and serotyping of E. coil from different pathological conditions in poultry. Indian Journal of Poultry Science 34: 366-369.

29. Shinebaum R and Cooke EM (1985). Klebsielles. In: Isolation and identification of micro-organisms of medical and veterinary importance. Collins, C. H. and Grange, J. M. (edn.). Academic Press, London, UK. pp. 35-40.

30. Smith HW and Haibs W (1967). Observation by the ligated intestinal segments and oral inoculation method of Escherichia coli in calves, lambs, pigs \& rabbits. Infection and Immunity 93: 499-529.

31. Stubbs EL (1954). Necropsy procedures for chickens and other birds. In: Veterinary Necropsy Procedures. Jones, T. C. (edn.). Journal of Bangladesh Lippincott Company, Philadelphia, USA. pp. 63-64.

32. Talha A FSM, Hossain MM, Chowdhury EH, Bari ASM, Islam MR and Das PM (2001). Poultry diseases occurring in Mymensingh district of Bangladesh. The Bangladesh Veterinary Journal 18: 20-23.

33. Thomas CGA (1988). Gram-negative Bacilli. Indian Medical Microbiology, $6^{\text {th }}$ edn. Bailliere Tindall. pp: 273-74.

34. Wani SA, Bhat MA, Samanta I, Nishikawa Y and Buchh AS (2003). Isolation and characterization of Shigella toxin-producing Escherichia coli and enteropathogenic Escherichia coli (EPEC) from calves and lambs with diarrhoea in India. Letters in Applied Microbialogy 37:121-126. 